\title{
Simulating the effects of temperature on individual and population growth of Rhinoptera bonasus: a coupled bioenergetics and matrix modeling approach
}

\author{
Julie A. Neer ${ }^{1,2, *}$, Kenneth A. Rose ${ }^{1}$, Enric Cortés ${ }^{2}$ \\ ${ }^{1}$ Department of Oceanography and Coastal Sciences and Coastal Fisheries Institute, Louisiana State University, Baton Rouge, \\ Louisiana 70803-7503, USA \\ ${ }^{2}$ NOAA Fisheries Service, 3500 Delwood Beach Road, Panama City, Florida 32408, USA
}

\begin{abstract}
Cownose rays Rhinoptera bonasus typify the K-selected life history strategy that makes their population dynamics susceptible to variation in natural and anthropogenic factors. We used an individual-based bioenergetics model, coupled to a matrix projection model, to predict how water temperatures warmer and cooler than current conditions would affect the individual growth and the population dynamics of cownose rays. The bioenergetics model simulated the daily growth, survival, and reproductive output of a cohort of female individuals from birth over their lifetime. Warmer and cooler temperature scenarios under alternative assumptions about ray movement were simulated. Under warmer conditions, daily consumption rate would have to increase by about $12 \%$ or weightsat-age would decrease by 10 to $17 \%$, while under cooler conditions, daily consumption would have to decrease by about $14 \%$ or weights-at-age would increase by about $15 \%$. Slowed individual growth under warmer water temperatures translated into slowed population growth rate, decreased net reproductive rate, longer generation time, and higher but delayed age-specific reproductive values. For example, under the scenario that resulted in the slowest individual growth rates, the population growth rate would decrease from 0.027 to $0.005 \mathrm{yr}^{-1}$. Population growth rates were more sensitive to variation in survival rates, especially those of mature age-classes, than to fertility rates. Our coupling of an individual-based bioenergetics model with a matrix projection model offers a potentially powerful approach for relating how, with limited to moderate information, changes in environmental variables and habitat that affect individual growth can be expressed as population-level responses.
\end{abstract}

KEY WORDS: Cownose ray $\cdot$ Bioenergetics $\cdot$ Matrix model $\cdot$ Population dynamics $\cdot$ Global climate change $\cdot$ Movement

Resale or republication not permitted without written consent of the publisher

\section{INTRODUCTION}

Cownose rays Rhinoptera bonasus, like many other elasmobranchs (sharks, skates, and rays), typify the K-selected life history strategy that makes their population dynamics especially susceptible to variation in natural and anthropogenic factors, including harvesting and habitat quality (Heppell et al. 1999, Russell 1999). In general, elasmobranchs are long-lived, late reproducing, low fecundity organisms, with many species having complex reproductive cycles and movement patterns (Compagno 1990). While all spe- cies do not behave identically, the slow life style of K-strategists makes their populations particularly sensitive to relatively small changes in their growth, mortality, and reproductive rates (Musick 1999).

Cownose ray abundance and distribution seems to be determined, at least in part, by water temperature (Smith \& Merriner 1987, Schwartz 1990). Cownose rays appear in the Chesapeake Bay when water temperatures reach $16^{\circ} \mathrm{C}$ in the spring, and usually begin their southward migration when water temperatures cool to $22^{\circ} \mathrm{C}$ in the fall (Smith \& Merriner 1987, Schwartz 1990). Along the northwest Florida shelf, 
rays begin to depart the area when the summer water temperatures are between 28 and $30^{\circ} \mathrm{C}$, and very few rays are captured at temperatures warmer than $30^{\circ} \mathrm{C}$ (Neer 2005). As waters cool to $28^{\circ} \mathrm{C}$ in early fall, the rays return to the region, where they remain until water temperatures drop below $18^{\circ} \mathrm{C}$ in early winter. Cownose rays are rarely collected at waters cooler than $15^{\circ} \mathrm{C}$ (Neer 2005). These documented movements of cownose rays in response to water temperature suggest that cownose rays may behaviorally thermoregulate to facilitate their growth or some other biological process (Matern et al. 2000), and that relatively small changes in water temperature could affect their population dynamics.

Water temperature can vary as a result of natural interannual and seasonal fluctuations, and as a result of global climate change. The average temperature in the United States could increase by 2 to $8^{\circ} \mathrm{C}$ over the next century due to the injection of greenhouse gases into the atmosphere in that region, with the most likely increase being around $4^{\circ} \mathrm{C}$ or less (Smith 2004). Increases in temperature due to global warming could have significant effects on aquatic ecosystems (Hill \& Magnuson 1990). Kennedy et al. (2002) state that, although summer temperatures in tropical waters may not increase much beyond present levels due to evaporative cooling, temperate and boreal regions may experience temperature increases that will be stressful or lethal for some organisms. Sub-lethal effects of warmer temperatures may include changes in metabolism, growth, and distribution (Kennedy et al. 2002).

In this paper, we used an individual-based bioenergetics model coupled to a matrix projection model to predict how water temperatures warmer than current conditions and cooler than current conditions would affect the individual growth and the population dynamics of the cownose ray in the northern Gulf of Mexico. Bioenergetics models use a balanced energy budget equation to estimate growth or production, or to predict consumption rates (Hanson et al. 1997). Bioenergetics modeling is appealing as it provides a link between fish physiology and environmental conditions, and provides a means for quantifying the relative importance of various environmental factors on individual growth or consumption (Brandt \& Hartman 1993). Our bioenergetics model was used to predict the effects of warmer and cooler water temperatures on the growth, survival, and reproductive output of individual rays over their lifetime. The outputs of the bioenergetics model were then used to estimate the parameters (inputs) of an age-based matrix projection model. Matrix projection models are based on a description of the life cycle of the species. Vital rates, such as birth, growth, maturation, fertility, and mortality, describe the progression of individuals through their life cycle, and the magnitudes of these rates determine the dynamics of the population over time. Eigenvalue analysis of the matrix projection model then allowed for the extrapolation of the growth, survival, and reproductive responses of individuals to the population level. Eigenvalue analysis produces estimates of population growth rate and other populationrelated variables under equilibrium conditions (i.e. once the stable age distribution has been obtained).

Age-structured matrix projection models, and associated life tables, have recently been used to examine the population dynamics of several elasmobranch species (e.g. Simpfendorfer 1999, Cortés 2002, 2004, Frisk et al. 2002). However, fully dynamic bioenergetics models of elasmobranchs have been limited (e.g. Du Preez et al. 1990, Schindler et al. 2002) compared to the widely studied teleost fishes, partially due to difficulties in performing experiments on elasmobranchs in captivity (Carlson et al. 2004). Our coupling of individual-based bioenergetics and age-structured matrix projection models demonstrates a powerful approach for relating the population level to changes in environmental conditions that affect growth, mortality, and reproduction of individuals.

Life history. The cownose ray ranges from southern New England to southern Brazil in the western Atlantic Ocean, as well as throughout the Gulf of Mexico and off the coast of Cuba (Bigelow \& Schroeder 1953, McEachran \& Fechhelm 1998). Rays are semipelagic and gregarious; often forming large schools, and rays are known to undertake long migratory movements (Schwartz 1990). Cownose rays are most often encountered on continental and insular shelves, where they feed primarily on bivalve mollusks and crustaceans (Smith \& Merriner 1985, McEachran \& Fechhelm 1998).

Cownose rays in the northern Gulf of Mexico exhibit a K-selected life history (Neer \& Thompson 2005). Verified age estimates indicate that cownose rays live in nature for at least $18 \mathrm{yr}$, with a predicted theoretical longevity of $26 \mathrm{yr}$. Fifty percent of the cownose ray population reaches maturity at age 4 to $5 \mathrm{yr}(\sim 4.6$ to $4.9 \mathrm{~kg}$ weight wet [ww]). Cownose rays reproduce annually, with females producing one pup per litter, with a gestation time of 11 to 12 mo. Cownose rays have few natural predators, with the exception of some large shark species such as the bull shark (J. Blackburn, pers. comm.). There is currently no directed fishery for cownose rays, although they are often taken as bycatch in a number of fisheries (Smith \& Merriner 1987, Trent et al. 1997). In the northern Gulf of Mexico, cownose rays are encountered at temperatures from 15 to $34^{\circ} \mathrm{C}$, and at salinities ranging from 17 to $37 \mathrm{ppt}$ (Neer 2005), suggesting that they are both eurythermal and euryhaline. 


\section{METHODS}

Bioenergetics model. The cownose ray bioenergetics model followed a cohort of 1000 female individuals from birth over their lifetime to either death or a maximum age of 25 yr. Numbers of individuals in the cohort were decremented daily based on a specified sizedependent mortality rate. Body weight of each individual ( $g$ ww) was updated daily based on a revised version of the Wisconsin bioenergetics formulation (Hanson et al. 1997). Size-dependent maturity was used to determine reproduction; weight loss associated with birth of a pup was based on observed average weight of pups at birth and was imposed each May 15 for all mature females. The model predicted daily survival, daily body weight, and annual pup production. Predictions were summarized as the number of individuals alive, average weight of an individual, and number of pups produced by year, which was equivalent to age since we followed a single cohort. We used the bioenergetics model to simulate the effects of cooler and warmer water temperature scenarios on cownose ray growth, survival, and reproductive output.

Water temperature: A daily temperature function was developed (see Fig. 1; gray line), starting on May 1 and ending on April 30, using data from the Panama City, Florida region, where the biological data used to develop and calibrate the model were also collected. Temperatures experienced by the cownose rays in baseline simulations were truncated at $30^{\circ} \mathrm{C}$, as field data demonstrated that rays begin to depart the area when water temperatures are between 28 and $30^{\circ} \mathrm{C}$ and very few rays are captured at temperatures warmer than $30^{\circ} \mathrm{C}$ (Neer 2005).

Mortality: Daily probability of dying was determined by fitting a decreasing curve between annual mortality rate and body weight (Roff 1992, Cortés 2004). Instantaneous annual natural mortality (IMR) was assumed to be 0.2 for the smallest individuals and decreased exponentially with weight, approaching 0.1 for the heaviest (oldest) individuals:

$$
\operatorname{IMR}=0.1+\left[0.6658 \cdot \mathrm{e}^{(-W / 921.49)}\right]
$$

where $W=$ weight ( $g$ ww). The upper mortality rate of $0.2 \mathrm{yr}^{-1}$ was calculated using a general equation between mortality rate and longevity (Hoenig 1983), while the lower value of $0.1 \mathrm{yr}^{-1}$ was based on reported rates for sandbar sharks and has been used previously in analysis of shark population dynamics (BrewsterGeisz \& Miller 2000). Annual mortality rates were converted to daily rates and if the randomly generated number from a uniform distribution was less than the daily probability of dying, then the individual died and was removed from the simulation.
Growth: Daily change in body weight was based on a mass balance equation:

$G_{\mathrm{S}}=\left\{\left[C_{\max } \cdot p \cdot f(T)\right]-\mathrm{M}_{\mathrm{R}}-\mathrm{SDA}-F-U\right\} \cdot \mathrm{C}_{\mathrm{F}}-G_{\mathrm{R}}$

where $G_{\mathrm{S}}=$ somatic growth; $C_{\max }=$ maximum consumption rate; $p=$ proportion of maximum consumption actually obtained; $f(T)=$ temperature dependence function; $T=$ water temperature $\left({ }^{\circ} \mathrm{C}\right) ; \mathrm{M}_{\mathrm{R}}=$ total respiration rate; $\mathrm{SDA}=$ metabolic costs of specific dynamic action; $F=$ egestion; $U=$ excretion; $C_{F}=$ caloric conversion factor, and $G_{\mathrm{R}}=$ growth used for reproduction. All rates, except growth used for reproduction $\left(G_{\mathrm{R}}\right)$, were in the units of $g$ prey $\mathrm{gray}^{-1} \mathrm{~d}^{-1}$. These rates were converted to $g$ prey $\mathrm{g} \mathrm{ray}^{-1} \mathrm{~d}^{-1}$ based on the ratio $\left(C_{\mathrm{F}}\right)$ of the caloric densities of ray to their prey. Model equations for growth are shown in Table 1, and associated parameter values are documented in Table 2. Age-specific values of $p$ were determined by calibration.

Realized consumption $(C)$ was estimated as the proportion $(p)$ of the maximum consumption rate. Estimates for the CA (intercept of the allometric mass function; in gprey $\mathrm{gray}^{-1} \mathrm{~d}^{-1}$ ) and CB (slope of the allometric mass function) parameters that governed the weight-dependence of maximum consumption rate were determined using available information on daily ration of elasmobranchs. The temperature dependence function for maximum consumption was a slowly rising function that reached 1 at a specific optimal temperature $\left(T_{\text {opt }}\right)$ and then declined to zero at a specific maximum temperature $\left(T_{\max }\right)$. A third parameter $(\mathrm{CQ})$, similar to a $Q_{10}$ parameter, dictated how rapidly the function increased for temperatures below $T_{\text {opt }}$. Once $\mathrm{CA}, \mathrm{CB}, \mathrm{CQ}$, and respiration-related parameters were specified, we iteratively solved for values of $T_{\text {opt }}$ and $T_{\max }$ to obtain realistic consumption rates.

Total daily respiration rate $\left(\mathrm{M}_{\mathrm{R}}\right)$ was computed as a standard respiration rate dependent on weight, and was then adjusted for temperature using a $Q_{10}$ relationship $(g(T))$ and adjusted for the metabolic cost of activity using a simple multiplier (ACT). Values for the RA (intercept of the allometric mass function; in $g$ prey g ray $^{-1} \mathrm{~d}^{-1}$ ) and RB (slope of the allometric mass function) parameters of standard respiration rate were obtained directly from experiments performed on cownose rays (Table 1; Neer et al. 2006), and the activity multiplier (1.9) was from experimental data for the bonnethead shark (J. K. Carlson unpubl. data). As with many bioenergetics models, specific dynamic action, egestion, and excretion were assumed to be proportional to realized consumption (Du Preez et al. 1988, 1990, Lowe 2002, Schindler et al. 2002). Caloric densities of prey and rays were assumed constant.

Reproduction: The probability of an individual reproducing at a given age was determined based on a logistic function that related the fraction of mature 
Table 1. Formulations and parameter values of growth-related components of cownose ray bioenergetics model. $T=$ daily temperature $\left({ }^{\circ} \mathrm{C}\right)$ experienced by individual ray

\begin{tabular}{|c|c|c|c|}
\hline Parameter & Equation & Units & Value \\
\hline Consumption $(C)$ & $p \cdot C_{\max }$ & g prey g ray ${ }^{-1} \mathrm{~d}^{-1}$ & \\
\hline$p$ & & proportion & $0.0-1.0$ \\
\hline$C_{\max }$ & $\mathrm{CA} \cdot W^{\mathrm{CB}} \cdot f(T)$ & g prey g ray $^{-1} \mathrm{~d}^{-1}$ & \\
\hline CA & & g prey $\mathrm{g} \mathrm{ray}^{-1} \mathrm{~d}^{-1}$ & 0.289 \\
\hline CB & & unitless & -0.374 \\
\hline CQ & & unitless & 2.33 \\
\hline$T_{\mathrm{opt}}$ & $J(1)$ & ${ }^{\circ} \mathrm{C}$ & 28.0 \\
\hline$T_{\max }$ & & ${ }^{\circ} \mathrm{C}$ & 36.0 \\
\hline Respiration & $\mathrm{RA} \cdot W^{\mathrm{RB}} \cdot g(T) \cdot \mathrm{ACT}$ & g prey g ray ${ }^{-1} \mathrm{~d}^{-1}$ & \\
\hline RA & & g prey $\mathrm{g} \mathrm{ray}^{-1} \mathrm{~d}^{-1}$ & 0.0068 \\
\hline RB & $\underline{T-T_{\text {ref }}}$ & unitless & -0.0919 \\
\hline$g(T)$ & $g(T)=\mathrm{KQ}_{10} \overline{{ }^{10}}$ & ${ }^{\circ} \mathrm{C}$ & \\
\hline $\mathrm{KQ}_{10}$ & & unitless & 2.33 \\
\hline$T_{\text {ref }}$ & & ${ }^{\circ} \mathrm{C}$ & 24.0 \\
\hline $\mathrm{ACT}$ & & unitless & 1.9 \\
\hline \multicolumn{4}{|l|}{ Reproduction } \\
\hline$G_{\mathrm{R}}$ & & g ww & 777 \\
\hline Specific dynamic action (SDA) & $\mathrm{KSDA} \cdot \mathrm{C}$ & g prey g ray ${ }^{-1} \mathrm{~d}^{-1}$ & \\
\hline KSDA & & proportion & 0.14 \\
\hline Egestion $(F)$ and excretion $(U)$ & $\mathrm{KFA} \cdot \mathrm{C}$ & g prey $\mathrm{g} \mathrm{ray}^{-1} \mathrm{~d}^{-1}$ & \\
\hline KFA & & proportion & 0.27 \\
\hline
\end{tabular}

Table 2. Estimation methods and data sources for growth component parameters of cownose ray bioenergetics model

\begin{tabular}{|c|c|}
\hline Growth component & Description and sources \\
\hline $\begin{array}{l}\text { Maximum } \\
\text { consumption }\left(C_{\max }\right)\end{array}$ & $\begin{array}{l}\text { CA and CB estimates determined using available information on daily ration of elasmobranchs } \\
\text { (e.g. Wetherbee \& Cortés } 2004 \text { ) and the Atlantic stingray Dasyatis sabina (Bradley 1996); additional } \\
\text { evidence indicates adult elasmobranch consumption rates may be one order of magnitude less than } \\
\text { those of pups (Van Dykhuizen \& Mollet 1992, E. Cortés unpubl. data). Various CA and CB } \\
\text { values substituted into } C_{\max } \text { equation ( } W \text { range } 1000-22000 \mathrm{~g} \text { ww) until } C_{\max } \text { ranged from } \sim 7 \% \\
\text { (small ind.) to } \sim 3 \% \text { (large ind.) BW d }{ }^{-1}\end{array}$ \\
\hline $\begin{array}{l}\text { Temp. effect on } \\
\text { consumption } \\
\left(\mathrm{CQ}, T_{\mathrm{opt}}, T_{\max }\right)\end{array}$ & $\begin{array}{l}\text { Values of CA and } \mathrm{CB} \text { as determined above, respiration-related parameters as in Neer et al. } \\
\text { 2006), and value of } p \text { set to } 0.5 \text {, various } T_{\text {opt }} \text { and } T_{\max } \text { values were substituted into consumption } \\
\text { equation until realistic realized consumption rates were obtained over a range of temperatures. } \\
\text { Starting values }\left(T_{\mathrm{opt}}=25^{\circ} \mathrm{C}, T_{\max }=35^{\circ} \mathrm{C} \text { ) as for bonnethead shark Sphyrna tiburo (J. K. Carlson }\right. \\
\text { unpubl. data), a similar active elasmobranch from same area as cownose rays. Realized consump- } \\
\text { tion target: that highest realized consumption rate occurs at } \sim 25^{\circ} \mathrm{C} \text { for a range of body weights, and } \\
\text { respiration rate is } 15-25 \% \text { of realized consumption rate (Hanson et al. 1997) }\end{array}$ \\
\hline $\begin{array}{l}\text { Standard respiration } \\
(\mathrm{RA}, \mathrm{RB})\end{array}$ & 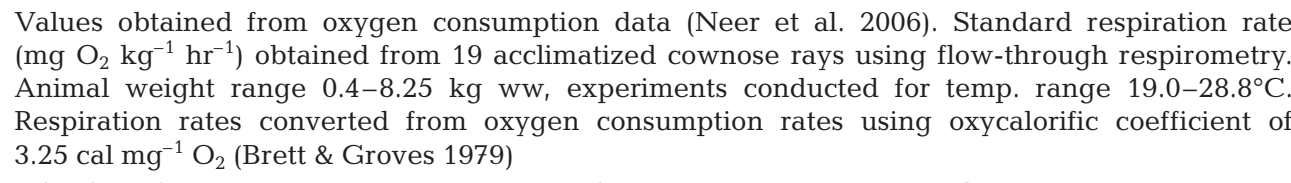 \\
\hline $\begin{array}{l}\text { Temperature effect } \\
\text { on respiration } \\
\left(\mathrm{KQ}_{10}, T_{\text {ref }}\right)\end{array}$ & $\begin{array}{l}\mathrm{KQ}_{10} \text { based on respiration rate variation within temp. range } 19.0-28.8^{\circ} \mathrm{C} \text { in respirometry experi- } \\
\text { ments (Neer et al. 2006). } T_{\text {ref }}=\text { Ave. temp. of oxygen consumption experiments used to estimate RA } \\
\text { and } \mathrm{RB}\end{array}$ \\
\hline $\begin{array}{l}\text { Activity multiplier on } \\
\text { respiration }(\mathrm{ACT})\end{array}$ & $\begin{array}{l}\text { As for bonnethead shark Sphyrna tiburo (J. K. Carlson unpubl. data), a similar active elasmobranch } \\
\text { from same area as cownose rays used in respiration experiments }\end{array}$ \\
\hline $\begin{array}{l}\text { Specific dynamic } \\
\text { action (KSDA) }\end{array}$ & $\begin{array}{l}\text { A KSDA value of } 0.14 \text { was used, as determined for the bull ray Myliobatus aquila at } 20^{\circ} \mathrm{C}(\mathrm{Du} \\
\text { Preez et al. 1988), a species with a similar autecology as the cownose ray. This is the only empirical } \\
\text { estimate of KSDA available for a batoid }\end{array}$ \\
\hline $\begin{array}{l}\text { Egestion and excretion } \\
\text { (KFA) }\end{array}$ & $\begin{array}{l}\text { As for lemon shark Negaprion brevirostris (Wetherbee \& Gruber 1993); sole empirical estimate } \\
\text { available for any elasmobranch (no estimates available for batoids), but elasmobranchs in general } \\
\text { have similar physiological traits }\end{array}$ \\
\hline $\begin{array}{l}\text { Caloric conversion } \\
\text { factor }\left(\mathrm{C}_{\mathrm{F}}\right)\end{array}$ & $\begin{array}{l}\text { Ray caloric density assumed to be } 1415 \mathrm{cal} \mathrm{g}^{-1} \mathrm{ww} \text { as for lemon shark Negaprion brevirostris } \\
\text { (Gruber 1984), as used in other elasmobranch studies (e.g. Wetherbee \& Gruber 1993, Schindler et } \\
\text { al. 2002); no estimate available for batoids, but elasmobranchs in general have similar physiologi- } \\
\text { cal traits. Bivalves (dominant prey of cownose rays) caloric density }=6390 \mathrm{cal} \mathrm{g}^{-1} \text { ww (Bradley } \\
\text { 1996). i.e. } C_{\mathrm{F}}=6390 / 1415=4.516\end{array}$ \\
\hline
\end{tabular}


individuals at that age to body weight (Neer \& Thompson 2005). If the random number drawn from a uniform distribution was smaller than the fraction mature based on an individual's weight on May 15 of the previous year, then the individual would reproduce in the current year. We used the weight from the previous year to mimic the 12 mo gestation period. The reproductive event was modeled by the loss of $777 \mathrm{~g} \mathrm{ww}$ on May 15, representing the average birth weight of one pup (Neer \& Thompson 2005).

Individual-level variability: Three sources of individual variability in ray growth were simulated: daily temperature experienced, weight-specific respiration rate, and daily value of $p$. For each day of the simulation, each ray was assigned a daily water temperature drawn from a normal distribution with the mean equal to the temperature predicted by the temperature function and a standard deviation of $1.5^{\circ} \mathrm{C}$. Minimum and maximum daily water temperature limits were set at plus and minus $2{ }^{\circ} \mathrm{C}$ of the daily generated mean temperature. This individual temperature variability was incorporated to account for the fact that all rays are not located in the same place, and therefore would experience similar, but not identical, daily temperatures. Mean daily water temperatures along the northwest Florida coast in areas where cownose rays occur varied by approximately 0.5 to $3^{\circ} \mathrm{C}$ during $2000-2002$ (National Ocean Services Center for Operational Oceanography Products and Services). Individual variability in the RA parameter of standard respiration was incorporated by assigning each ray a value of RA drawn from a normal distribution with a mean set to a calibrated value of 0.0068 and a coefficient of variation (CV) of $5 \%$. Variation in values of RA was a crude way to allow for individual variation in growth efficiency. Rays were assigned individual daily values of $p$ from a normal distribution having a mean of the age-specific $p$-value determined through the calibration process, and a CV of $5 \%$. Variability in values of $p$ was incorporated to reflect the variability in prey encountered and ingested among individual rays, as well as variability in prey capture ability.

Initial conditions: All simulations of the bioenergetics model started with 1000 female individuals on May 1. Initial weights ( $g \mathrm{ww}$ ) were generated from a normal distribution with a mean of $777 \mathrm{~g}$ ww and a standard deviation of $171 \mathrm{~g}$ ww. Minimum (500 g ww) and maximum (1000 g ww) initial weights were imposed to ensure realistic initial weights based on observed weight-at-birth information (Neer \& Thompson 2005).

Calibration of values of p: Values of $p$ were determined for each year (age) of the $25 \mathrm{yr}$ simulation by calibration. Iterative simulations were performed that adjusted each age's $p$-value until the model-simulated daily growth resulted in a predicted weight at the end of each age that matched observed weights-at-age determined from field data (Neer \& Thompson 2005). We used a bisection algorithm to determine successive values of $p$, and stopped when predicted mean weight was within $1 \%$ of the observed mean weight for each age.

Matrix projection model. We used an age-structured matrix projection model to analyze the population-level consequences of the cooler and warmer water temperature scenarios. The predictions of the bioenergetics model of growth, survival, and reproductive output under baseline, cooler, and warmer scenarios were used to estimate the parameters of matrix projection models. We then analyzed the resulting matrix projection models to obtain estimates of population growth rate, the stable age-distribution, reproductive values by age, and elasticity.

The matrix projection model followed females using a birth-pulse structure with a post-breeding census (Caswell 2001). Annual survival rates (sub-diagonal elements) and fertility values, (top row; defined as $f_{i}=P_{i} \cdot m_{i}$ where $f_{i}=$ fertility at age $i, P_{i}=$ age-specific survival probability and $m_{i}=$ age-specific reproductive output) of each $25 \times 25$ matrix were estimated from the numbers surviving and pup production (number of pups per female) predicted by the bioenergetics model. The age-specific fecundity estimates predicted by the bioenergetics model were divided by 2 to reflect a 1:1 male:female sex ratio (Neer \& Thompson 2005).

For each scenario, we estimated a matrix model and computed finite and instantaneous population growth rates, net reproductive rate, generation time, stable age distribution, and age-specific reproductive values and elasticities. Net reproductive rate is the mean number of offspring by which a newborn will be replaced by the end of its lifetime. There are 3 commonly used measures of generation time (Caswell 2001), whose differences can, in some circumstances, be important. In our analysis, all 3 formulations produced very similar estimates. We have therefore only reported one of the generation time measures $\left(\bar{A}_{i}\right.$ mean age of the parents of the offspring produced by a population at the stable age distribution), which is the most commonly used measure in elasmobranch studies (e.g. Cortés 2002, Mollet \& Cailliet 2002). Reproductive value is the number, relative to a value of 1 for the first age-class, of offspring that are yet to be born by individuals in a given age class (Gotelli 2001). If a population is growing at its instantaneous growth rate, the population will eventually converge on a stable age distribution (i.e. reach equilibrium), where the proportion of individuals in each age class remains constant. Elasticity is the proportional change in the finite population growth rate due to changes in fertility and survival (i.e. elements in the projection matrix; Heppell et 
al. 2000). We report age-specific elasticities, and also elasticities summed over ages (aggregated elasticities) to examine the overall effects of fertility (all ages), juvenile (age 1 to 4 yr) survival, and adult (age $\geq 4$ yr) survival on that rate (Heppell et al. 2000). All calculations were completed using the PopTools add-in to Excel (www.cse.csiro.au/ poptools/).

Design of model simulations. Cooler and warmer water temperature scenarios and thermoregulation: Five temperature scenarios were simulated using the bioenergetics and matrix projection models (Fig. 1). These temperature scenarios were baseline conditions (representing present day water conditions), and a $2{ }^{\circ} \mathrm{C}$ warmer scenario and a $2^{\circ} \mathrm{C}$ cooler scenario, each under the assumption of thermal refuges or restricted movement for cownose rays. The increase of $2^{\circ} \mathrm{C}$ was selected to crudely mimic warmer than average years or the moderate level changes predicted by global climate change (Smith 2004). The decrease in $2^{\circ} \mathrm{C}$ was conducted to examine the symmetry of response of the rays to temperature variation around the average (baseline) conditions.

Recent research (e.g. Matern et al. 2000) suggests that some elasmobranchs, like many species of teleosts (Neill 1979, Hill \& Magnuson 1990), may behaviorally thermoregulate and seek out temperatures close to their optimal temperature. The maximum daily water temperature allowed to be experienced by the cownose ray for the baseline scenario was $30^{\circ} \mathrm{C}$ (i.e. truncated at $30^{\circ} \mathrm{C}$; baseline in Fig. 1), as field data demonstrated that rays left the study area at warmer water temperature. Alternative temperature truncations at warm temperatures were done to mimic the thermal refuges versus restricted movement assumptions (Fig. 1).

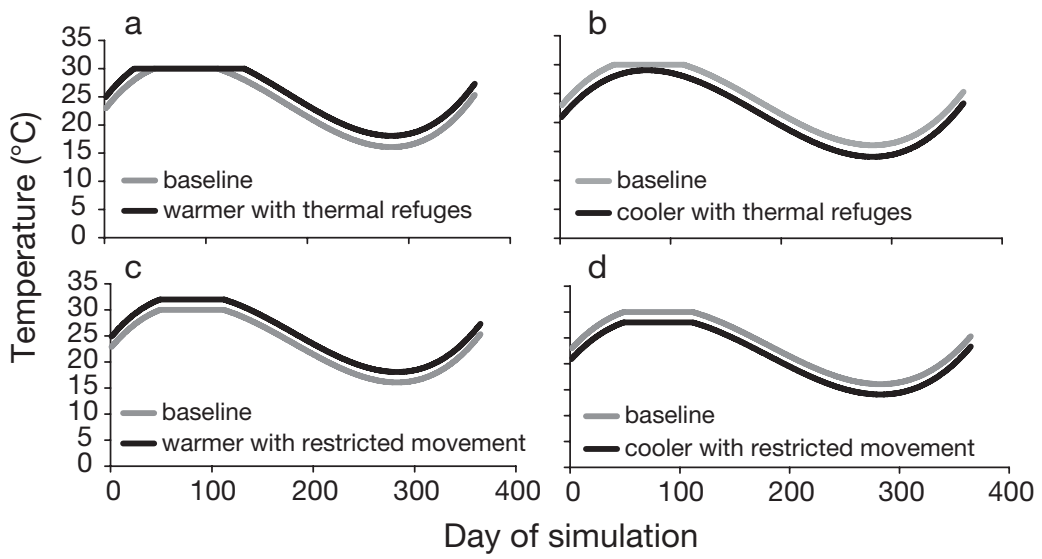

Fig. 1. Average daily temp. experienced by rays in bioenergetics model for combinations of baseline, warmer, and cooler scenarios with 2 alternative movement assumptions (thermal refuges vs. restricted). Baseline shown on all graphs and truncated at max. temp. of $30^{\circ} \mathrm{C}$. Day $1=$ May 1 . Temp. data provided by National Marine Fisheries Service (J. K. Carlson unpubl. data) and National Ocean Services Center for Operational Oceanography Products and Services for Panama City, Florida
In all of our scenarios, we assumed that the cownose rays would respond to water warmer than $30^{\circ} \mathrm{C}$, and not change their behavior in response to water cooler than $30^{\circ} \mathrm{C}$. The thermal refuges scenarios in model simulations assumed that, on days when temperature exceeded $30^{\circ} \mathrm{C}$, if needed, cownose rays would find additional locations (i.e. refuges) to those used under baseline conditions that had a maximum temperature of $30^{\circ} \mathrm{C}$. To simulate this, the maximum daily temperature was truncated at $30^{\circ} \mathrm{C}$ after the $2^{\circ} \mathrm{C}$ increase under the warmer scenario (Fig. 1a). No truncation was needed under the cooler scenario because once baseline temperatures were lowered by $2^{\circ} \mathrm{C}$ they never exceeded $30^{\circ} \mathrm{C}$ (Fig. 1b); cownose rays could move around and never need to seek out refuge locations. The restricted movement assumption presumed that cownose rays were unable to move around enough to find additional cooler water other than the locations they used under baseline conditions. In this case, the truncation at $30^{\circ} \mathrm{C}$ occurred before the $2^{\circ} \mathrm{C}$ was added or subtracted. This resulted in temperature being truncated at $32^{\circ} \mathrm{C}$ under the warmer scenario (Fig. 1c) and at $28^{\circ} \mathrm{C}$ under the cooler scenario (Fig. 1d) because in both situations, the restricted movement would have the rays using the same refuge locations as they used in baseline, which are now either $2^{\circ} \mathrm{C}$ warmer or cooler.

In all simulations, some rays experienced slightly warmer temperatures than $30^{\circ} \mathrm{C}$ due to individual variability in temperatures being applied after the truncations of the daily mean at $30^{\circ} \mathrm{C}$. For simplicity, we label our scenarios as warmer or cooler with thermal refuges or restricted movement, recognizing that our use of truncation to simulate the scenarios resulted in asymmetric changes to the temperature time series among the 4 scenarios.

Bioenergetics and matrix model simulations: The bioenergetics model was run in 2 different modes (temperature effect and consumption effect) for each of the 5 temperature scenarios, with the temperature effect mode output providing inputs to configure matrix projection models (Table 3). The temperature effect mode examined the effect of a daily temperature change on the predicted growth of individuals, given that the values of $p$ were held at baseline calibrated values. This assumed that the cownose rays would not change their foraging in response to altered water temperatures, and that prey dynamics remained the same as in baseline conditions. Because values of $p$ were fixed, temperature effect simula- 
Table 3. Combinations of bioenergetics model simulations and matrix projection model analyses used in this paper. Movement assumption (thermal refuges vs. restricted) affected truncation point of altered water temp. when this exceeded rays' upper tolerance limit of $30^{\circ} \mathrm{C}$

\begin{tabular}{|c|c|c|c|c|}
\hline \multirow[t]{2}{*}{ Mode } & \multirow[t]{2}{*}{ Temp. scenario } & \multirow{2}{*}{$\begin{array}{l}\text { Movement } \\
\text { assumption }\end{array}$} & \multicolumn{2}{|c|}{ Model outputs } \\
\hline & & & Bioenergetics & Matrix projection \\
\hline \multirow[t]{4}{*}{ Consumption } & Baseline & Thermal refuges & \multirow[t]{2}{*}{ Re-calibrated values of $p$} & \multirow{10}{*}{$\begin{array}{c}\text { Reproductive values } \\
\text { by age } \\
\text { Elasticities }\end{array}$} \\
\hline & Warmer & Thermal refuges & & \\
\hline & & Restricted & \multirow{2}{*}{$\begin{array}{l}\text { Also expressed as changes in } \\
\text { daily consumption }\end{array}$} & \\
\hline & Cooler & $\begin{array}{l}\text { Thermal refuges } \\
\text { Restricted }\end{array}$ & & \\
\hline \multirow[t]{6}{*}{ Temperature } & Baseline & Thermal refuges & \multirow{3}{*}{$\begin{array}{c}\text { Annual age-specific } \\
\text { survival }\end{array}$} & \\
\hline & Warmer & Thermal refuges & & \\
\hline & & Restricted & & \\
\hline & \multirow[t]{3}{*}{ Cooler } & Thermal refuges & \multirow{3}{*}{$\begin{array}{l}\text { Maturity and reproductive } \\
\text { output by age }\end{array}$} & \\
\hline & & Restricted & & \\
\hline & & & & \\
\hline
\end{tabular}

tions of the bioenergetics model predicted changes in weight, and therefore changes in survival and reproductive rates. The matrix projection model extrapolated these changes in survival and reproduction to the population level.

The consumption effect simulations examined how the age-specific values of $p$ would have to change under the altered temperature scenarios in order for the rays to maintain the baseline (i.e. field-determined) weights-at-age. We allowed the age-specific values of $p$ to be re-estimated for each of the 4 altered temperature scenarios. Because values of $p$ were allowed to change, predicted weights-at-age, and therefore survival and reproduction, were virtually identical to baseline values.

For simulations in the temperature effect mode, we compared predicted weights-at-age, survival by age, and reproduction (maturity and number of pups per female) by age between the baseline scenario and the 4 altered temperature scenarios. For simulations in the consumption effect mode, we reported the percent changes in values of $p$ by age between the altered temperature and baseline conditions. We also expressed the changes in values of $p$ as the corresponding changes in daily consumption rate (\% body weight [BW] $\mathrm{d}^{-1}$ ).

We report the results from one of the 3 replicate simulations of the bioenergetics model. Replicate simulations used different random number sequences that affected the stochastic aspects of the bioenergetics model, including initial weights, survival, and maturity. We report the results of a single replicate simulation because differences among replicates in predictions of weights-at-age were less than $2 \%$ among all temperature scenarios. The matrix projection models were all deterministic so single predictions are reported.

\section{RESULTS}

\section{Bioenergetics model}

Model-predicted weights-at-age under baseline conditions closely matched the mean weights from a Gompertz growth curve and individual measurements derived from observed size-at-age data (Fig. 2, Neer \& Thompson 2005). This good fit was expected, as the

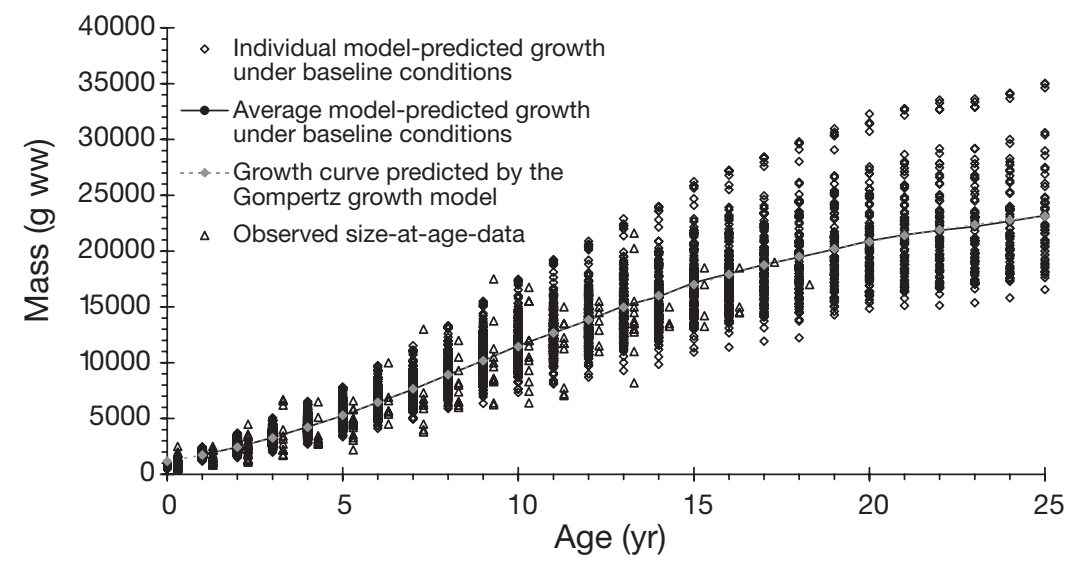

Fig. 2. Bioenergetics model predictions of average and individual weights-atage for baseline conditions (calibration), compared with weights-at-age from fitted Gompertz growth curve and individual measurements from field data. Observed size-at-age data offset for clarity 
Table 4. Predicted reproductive output (number of female pups per female) by age for combinations of baseline, cooler, and warmer scenarios with 2 alternative movement assumptions (thermal refuges vs. restricted). Predictions from bioenergetics model run in temp. effect mode

\begin{tabular}{|c|c|c|c|c|c|}
\hline \multirow[b]{2}{*}{ Age } & \multirow[b]{2}{*}{ Baseline } & \multicolumn{2}{|c|}{ - Warmer } & \multicolumn{2}{|c|}{ Cooler } \\
\hline & & $\begin{array}{l}\text { Thermal } \\
\text { Refuges }\end{array}$ & Restricted & $\begin{array}{l}\text { Thermal } \\
\text { Refuges }\end{array}$ & Restricted \\
\hline 1 & 0.000 & 0.000 & 0.000 & 0.000 & 0.000 \\
\hline 2 & 0.000 & 0.000 & 0.000 & 0.000 & 0.000 \\
\hline 3 & 0.000 & 0.000 & 0.000 & 0.000 & 0.000 \\
\hline 4 & 0.004 & 0.002 & 0.000 & 0.003 & 0.010 \\
\hline 5 & 0.024 & 0.011 & 0.009 & 0.063 & 0.080 \\
\hline 6 & 0.141 & 0.099 & 0.055 & 0.214 & 0.245 \\
\hline 7 & 0.288 & 0.235 & 0.169 & 0.390 & 0.400 \\
\hline 8 & 0.435 & 0.372 & 0.330 & 0.466 & 0.467 \\
\hline 9 & 0.474 & 0.440 & 0.423 & 0.485 & 0.489 \\
\hline 10 & 0.495 & 0.480 & 0.472 & 0.497 & 0.492 \\
\hline 11 & 0.496 & 0.495 & 0.487 & 0.498 & 0.496 \\
\hline $12-25$ & 0.496 & 0.500 & 0.492 & 0.496 & 0.496 \\
\hline
\end{tabular}

Table 5. Predicted percent maturity by age for combinations of baseline, cooler, and warmer scenarios with 2 alternative movement assumptions (thermal mode refuges vs. restricted). Predictions from bioenergetics model run in temp. effect

\begin{tabular}{|ccccccc|}
\hline & & \multicolumn{2}{c}{ Warmer } & & \multicolumn{2}{c|}{ Cooler } \\
\cline { 3 - 4 } Age & Baseline & Thermal & Restricted & & Thermal & Restricted \\
& & Refuges & & & & \\
\hline 1 & 0.0 & 0.0 & 0.0 & 0.0 & 0.0 \\
2 & 0.0 & 0.0 & 0.0 & 0.0 & 0.0 \\
3 & 0.0 & 0.0 & 0.0 & 0.0 & 0.0 \\
4 & 0.8 & 0.4 & 0.0 & 0.5 & 1.9 \\
5 & 4.7 & 2.3 & 1.7 & 12.7 & 15.9 \\
6 & 28.1 & 19.8 & 11.0 & 42.7 & 49.0 \\
7 & 57.7 & 47.0 & 33.8 & 78.0 & 80.0 \\
8 & 87.0 & 74.4 & 66.1 & 93.3 & 93.3 \\
9 & 94.7 & 88.0 & 84.6 & 96.9 & 97.7 \\
10 & 98.9 & 96.0 & 94.4 & 99.3 & 98.4 \\
11 & 99.2 & 99.1 & 97.5 & 99.6 & 99.3 \\
$12-25$ & 99.1 & 100.0 & 98.3 & 99.2 & 99.2 \\
\hline
\end{tabular}

values of $p$ would need to be 1.4 to $3.8 \%$ greater than the baseline calibrated values (mean increase over all ages of $2.8 \%$ ) in order for rays to achieve baseline weights-at-age under warmer conditions; that is, cownose rays would have to consume approximately $12.0 \%$ more $\mathrm{BW} \mathrm{d}^{-1}$ (range over ages: 10.4 to $13.0 \% \mathrm{BW} \mathrm{d}^{-1}$ ).

Under the restricted movement assumption, warming generated a larger reduction in growth and greater demands on consumption than under the thermal refuges assumption (Fig. 3). Weights-at-age predicted under the restricted movement assumption averaged 16.8\% smaller (range: 11.5 to $19.4 \%$ ) than baseline values. The new calculated age-specific values of $p$ averaged $5.2 \%$ higher (range: 4.1 to $6.7 \%$ ) than baseline values, meaning that rays would need to consume about $11.7 \%$ more BW $\mathrm{d}^{-1}$ to achieve baseline weights-at-age.

Using the thermal refuges assumption, cooler temperatures resulted in faster growth compared to the baseline conditions (Fig. 3). Mean weights-atage increased by an average of $13.4 \%$ (range: 6.9 to $16.4 \%$ ) over baseline conditions. Percent reductions in $p$-values from baseline values averaged $3.7 \%$ (range: 2.6 to $4.8 \%$ ), meaning that rays needed to consume an average of $12.7 \%$ less BW $\mathrm{d}^{-1}$ (range: 13.0 to $14.5 \%)$ to maintain baseline weightsat-age.

Restricted movement produced simimodel was calibrated to these same data. Estimated values of $p$ by age under baseline conditions increased with age and varied from 0.414 for age $1 \mathrm{yr}$ to 0.828 for age 25 yr. Age-specific annual survival ranged from 74 to $95 \%$, with an average annual survival over all age classes of $90 \%$. Predicted pup production and maturity were initiated at age $4 \mathrm{yr}$ and reached their maximum values by about age 10 yr (Tables 4 \& 5).

Under the thermal refuges assumption, fixing values of $p$ at baseline values (temperature effect mode) resulted in warming causing slowed growth when compared to the baseline scenario (Fig. 3). Agespecific average weights were between 4.8 and $11.2 \%$ smaller compared to baseline values; the overall average decrease in weight-at-age (averaged over all ages) was $9.6 \%$. Allowing the values of $p$ to be re-calibrated (consumption effect mode) showed that age-specific lar results as the thermal refuges assumption (Fig. 3). Weights-at-age increased by an average of $17.2 \%$ (range: 10.4 to $20.2 \%$ ). Age-specific $p$-values decreased an average of $4.4 \%$ (range: 3.3 to $5.3 \%$ ), meaning that rays would need to consume an average of $13.6 \%$ less BW d ${ }^{-1}$ (range: 13.0 to $14.5 \%$ ) to achieve baseline weights-at-age.

Changes in reproductive output by age predicted by the bioenergetics model in the temperature effect mode varied among the temperature scenarios (Table 4 ), and were caused by growth differences affecting the percent of individuals mature by a given age (Table 5). The most delayed maturity and lowest reproductive output was predicted under the slowest growth (i.e. warmer with restricted movement assumption), while the earliest maturation and highest reproductive output was predicted for the fastest growth (i.e. cooler 


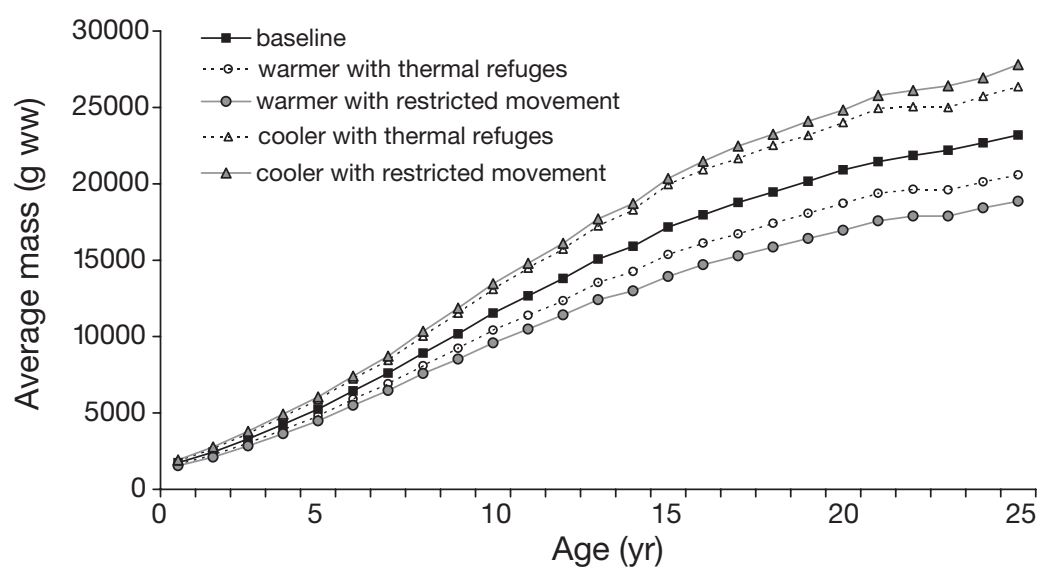

Fig. 3. Predicted average weights of all individuals alive on April 30 of each year for combinations of baseline, warmer, and cooler scenarios with 2 alternative movement assumptions (thermal refuges vs. restricted). Predictions from bioenergetics model run in temp. effect mode

with restricted movement). For example, reproductive output and maturity at age 7 yr were 0.169 pups per female and $33.8 \%$ for the warmer with restricted movement assumption, and 0.4 pups per female and $80 \%$ for the cooler with restricted movement scenario. Baseline and the other 2 temperature scenarios generated reproductive output and maturity by age values intermediate to these 2 extreme scenarios.

The number of individuals surviving to each age predicted by the bioenergetics model under the temperature effect mode was higher than baseline under the cooler scenarios and lower than baseline under the warmer scenarios (Fig. 4). The largest differences in survival were predicted for the intermediate age classes. Overall survivorship from birth to age $25 \mathrm{yr}$ was $5.0 \%$ under baseline, $\sim 4.5 \%$ for the warmer scenarios, and $\sim 6.0 \%$ for the cooler scenarios.

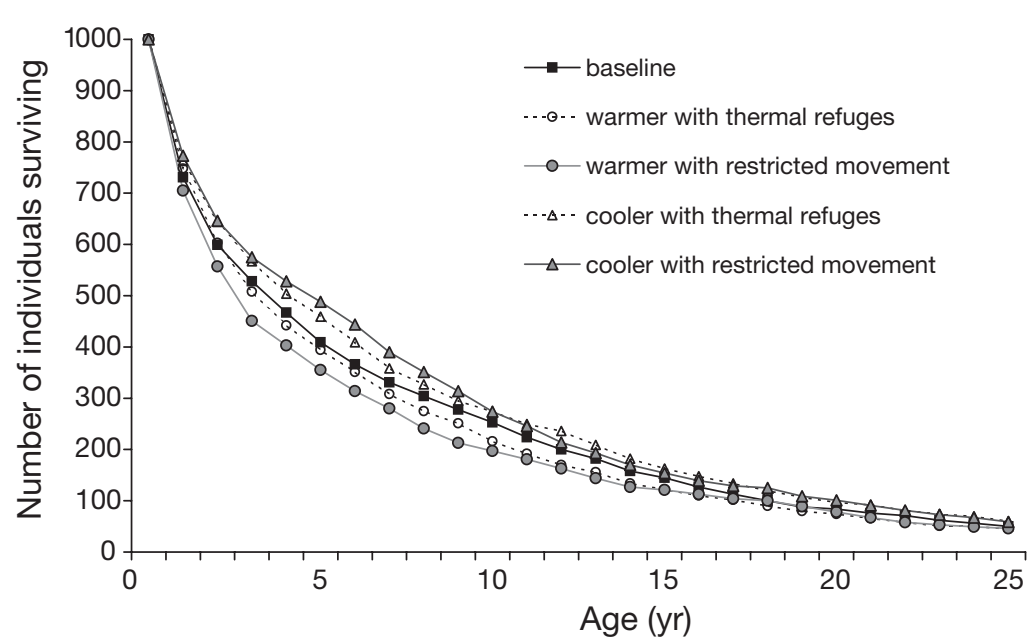

Fig. 4. Predicted survivorship curves for combinations of baseline, warmer, and cooler scenarios with 2 alternative movement assumptions (thermal refuges vs. restricted). Predictions from bioenergetics model run in the temperature effect mode

\section{Matrix projection model}

The slowed growth of individuals under warmer temperatures, and associated changes in reproduction and survival rates, resulted in slowed population growth rate, reduced reproductive rates, and longer generation times, while the faster individual growth under cooler temperatures resulted in faster population growth rate, increased reproductive rate, and shorter generation time (Table 6). Instantaneous population growth rate was $0.027 \mathrm{yr}^{-1}$ for baseline, decreased under warmer conditions to $0.012 \mathrm{yr}^{-1}$ for thermal refuges and to $0.005 \mathrm{yr}^{-1}$ for restricted movement, and increased under cooler conditions to $0.043 \mathrm{yr}^{-1}$ for thermal refuges and to $0.046 \mathrm{yr}^{-1}$ for restricted movement. The shortest generation time (11.4 yr) and the highest net reproductive rate (1.73 females per female over her lifetime) was predicted for the fastest growth scenario (i.e. cooler with restricted movement), while the longest generation time (13.8 yr) and lowest net reproductive rate (1.07 females per female over her lifetime) was predicted for the slowest growth scenario (i.e. warmer with restricted movement assumption).

Stable age distributions showed little response to altered temperatures (Fig. 5), and warmer and cooler conditions predicted relatively small shifts in the ages of peak reproductive values (Fig. 6). The cooler temperature scenarios consistently had slightly greater proportions in the younger age classes than the stable age distributions under the baseline and warmer scenarios, but differences were very small in magnitude. Under warming, lower survival and slower growth resulted in a somewhat delayed peak in reproductive values compared to baseline (Fig. 6). The higher survival and faster growth under cooler conditions, particularly under restricted movement, resulted in reproductive values with age that tended to have broader and earlier peaks.

Age-specific and aggregated elasticities to survival were larger than elasticities related to fertility (Fig. 7). Elasticity to survival for juvenile ages was greatest for the cooler scenarios, intermediate for baseline, and lowest for warmer scenarios, and this pattern reversed for elasticity aggregated across mature ages. Elasticities to fertility were smaller than for survival, and differences among temper- 
Table 6. Population growth rates $\left(\mathrm{yr}^{-1}\right)$, net reproductive rate (females per female over her lifetime), and generation time (yr) calculated from matrix projection model for combinations of baseline, cooler, and warmer scenarios with 2 alternative movement assumptions (thermal refuges vs. restricted). Matrix models configured from outputs of bioenergetics model run in temp. effect mode

\begin{tabular}{|lccccc|}
\hline Scenario & $\begin{array}{c}\text { Movement } \\
\text { assumption }\end{array}$ & $\begin{array}{c}\text { Finite } \\
\text { population } \\
\text { growth } \\
\text { rate }\end{array}$ & $\begin{array}{c}\text { Instantaneous } \\
\text { population } \\
\text { growth } \\
\text { rate }\end{array}$ & $\begin{array}{c}\text { Net } \\
\text { repro- } \\
\text { ductive } \\
\text { rate }\end{array}$ & $\begin{array}{c}\text { Generation } \\
\text { time }\end{array}$ \\
\hline Baseline & Thermal refuges & 1.027 & 0.027 & 1.411 & 12.4 \\
Warmer & $\begin{array}{c}\text { Thermal refuges } \\
\text { Restricted }\end{array}$ & 1.012 & 0.012 & 1.177 & 13.0 \\
Cooler & $\begin{array}{c}\text { Thermal refuges } \\
\text { Restricted }\end{array}$ & 1.005 & 0.005 & 1.070 & 13.8 \\
& 1.047 & 0.043 & 1.696 & 11.8 \\
\hline
\end{tabular}

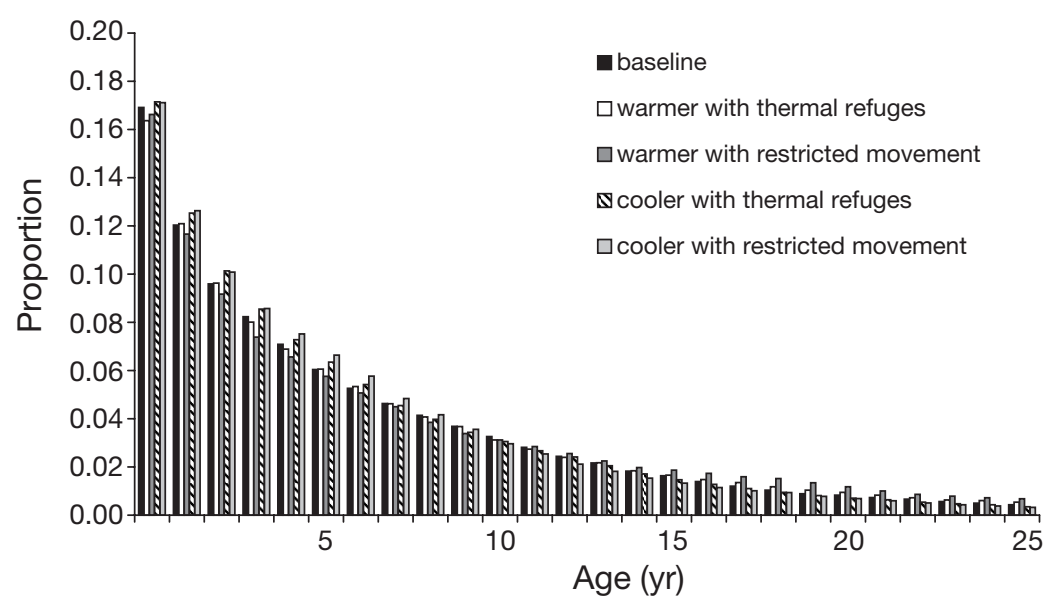

Fig. 5. Stable age distributions calculated from the matrix projection models for combinations of baseline, warmer, and cooler scenarios with 2 alternative movement assumptions (thermal refuges vs. restricted)

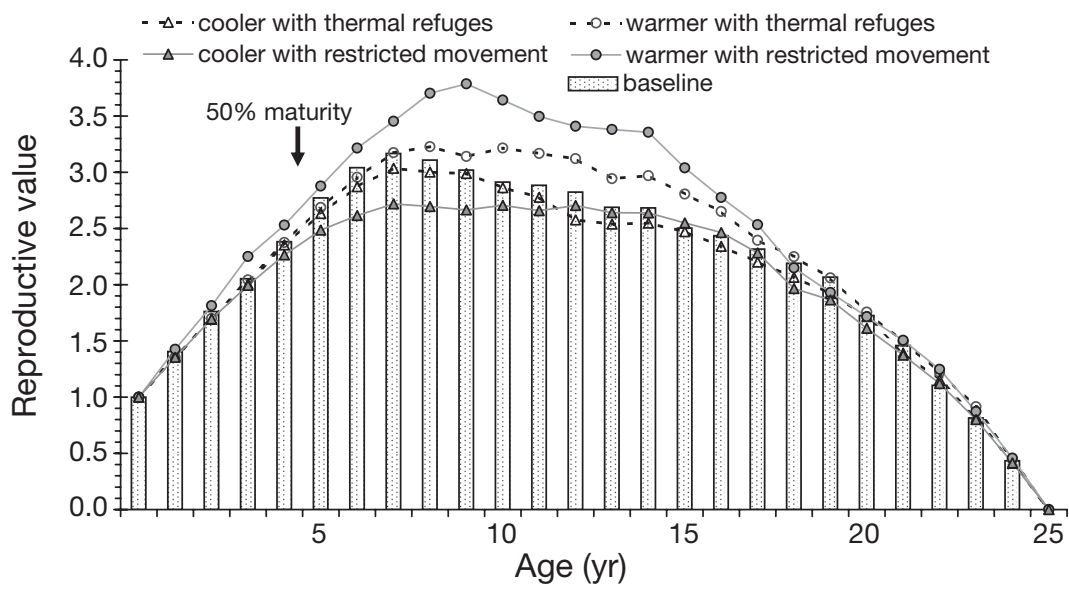

Fig. 6. Age-specific reproductive values calculated from the matrix projection models for combinations of baseline, warmer, and cooler scenarios with 2 alternative movement assumptions (thermal refuges vs. restricted). Also shown: field determination of $50 \%$ maturity ature scenarios, while consistent with elasticities to survival, were very small in magnitude. Aggregated elasticities were very similar among scenarios, with elasticity to adult survival the highest ( 0.65), elasticity to juvenile survival intermediate $(\sim 0.25)$, and elasticity to fertility the lowest $(\sim 0.08)$.

\section{DISCUSSION}

Our bioenergetics simulations in consumption mode suggested that realized daily consumption rate would have to significantly change under the different temperature scenarios and movement assumptions for simulated average weights-at-age to match historical weights-at-age. Rays would need to consume approximately $11 \% \mathrm{BW} \mathrm{d}^{-1}$ more energy over their entire lifetime under warmer conditions to achieve baseline weights-at-age. This would imply that rays would have to alter their foraging behavior to increase prey consumption, as shifts in diet are unlikely because the caloric content of their bivalve prey is already high. Whether rays would be able to increase their prey consumption in nature to compensate for the increased metabolic cost incurred under warmer water temperatures is unknown. A decrease in consumption of similar magnitude (11 to $13 \% \mathrm{BW} \mathrm{d}^{-1}$ ) under the cooler scenarios would be necessary for rays to achieve their baseline weights-at-age.

Bioenergetics model simulations in temperature effect mode suggested that changes in individual cownose ray growth rates in response to warmer and cooler temperatures depended on assumptions about ray movement. The predicted decrease in weights-at-age under warmer conditions for the restricted movement assumption (average of $16.8 \%$ over all ages) was almost twice that predicted for the thermal refuges assumption (average of 9.6\% over all ages). In contrast, under the cooler temperature scenario, both the restricted movement and thermal refuges assumptions predicted more similar increases in weights-at-age be- 


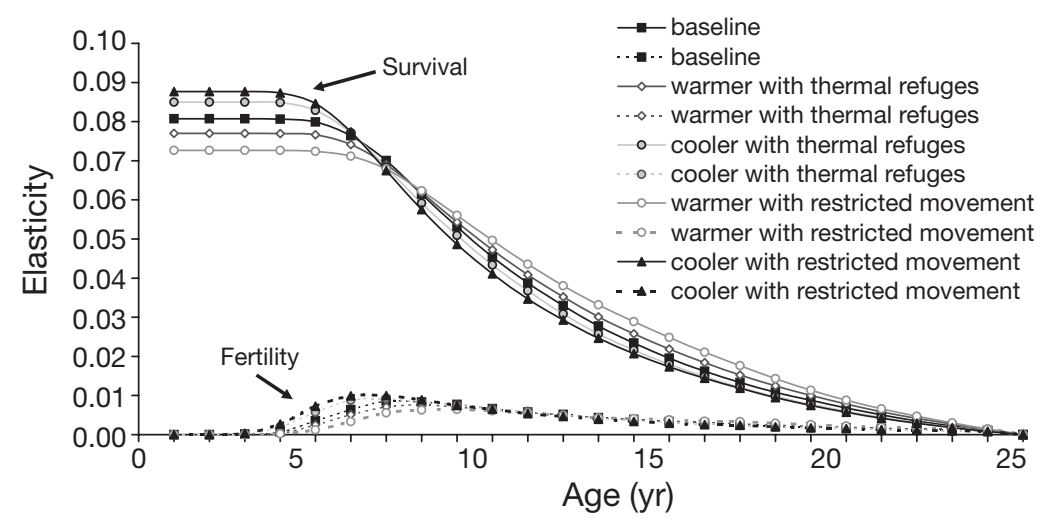

Fig. 7. Age-specific elasticities of survival and fertility calculated from matrix projection models for combinations of baseline, warmer, and cooler scenarios with 2 alternative movement assumptions (thermal refuges vs. restricted). Solid lines = survival elasticities; dashed lines = fertility elasticities for each combination resilience, making even what appear to be small changes in growth and population-level responses, such as our predictions, worthy of attention (Heppell et al. 1999, Rose et al. 2001, Cortés 2002).

Population growth rates of cownose rays are more sensitive to variation in age-specific survival rates than to agespecific fertility rates (Fig. 7). The importance of survival has also been documented for other long-lived species (Heppell et al. 1999). In our analysis, population growth rate was relatively insensitive to variation in fertility rates. Frisk et al. (2002) examined the demographics of 3 species of skates and suggested that for species with low tween movement assumptions (17.2 and 13.4\%, averaged over all ages). Matern et al. (2000) suggested that bat rays Myliobatis californica behaviorally thermoregulated to maximize their feeding efficiency. They suggested that bat rays utilized warmer waters during the day to enhance their foraging and then used cooler waters at night to increase digestive times. Our results implied that, while warmer temperatures may provide a short-term advantage to certain behaviors such as foraging, warmer conditions would have a negative long-term (life time) effect whose magnitude would depend upon the movement abilities of the cownose rays.

Differences in individual growth rates predicted by the bioenergetics model in temperature effect mode can be expressed as population-level responses. The matrix projection models predicted that, under equilibrium conditions (i.e. attainment of the stable age distribution), slowed individual growth under warmer water temperatures would translate into slowed population growth rate, decreased net reproductive rate, and longer generation times (Table 6). Interestingly, predicted stable age distributions were similar among all temperature scenarios (Fig. 5), and while reproductive values with age showed some shifts under the temperature scenarios, intermediate ages were always indicated as important (Fig. 6). Cooler temperatures would have the opposite effect, suggesting that, at least according to our models, cownose rays are near their thermal maximum. Whether our predicted bioenergetics and population dynamics changes have biological significance in nature is not clear. Predicted responses based on our coupled models would need to be viewed in the context of the variability generated by unmet assumptions (e.g. movement, equilibrium), uncertain parameter values, and variation from the many other sources not included in the models. The 'K-strategy' life history of cownose rays results in a population with relatively low resistance and fecundity, a trade-off between somatic growth and reproductive output could cause population growth rate to be insensitive to fertility. The insensitivity to fertility of cownose rays relates to their very low fecundity (one pup per litter and one litter per year) and the fact that only small changes in fecundity are possible due to biological constraints, such as limited space available for a female to carry any additional young.

Aggregated elasticities indicated that population growth rate was most sensitive to variation in adult survival. Evidence from other analyses of elasmobranchs appears contradictory over the importance of juvenile survival versus mature adult survival. Frisk et al. (2002) reported that adult survival had the greatest effect on population growth rate of the barndoor skate Dipturus laevis and Mollet \& Cailliet (2002) reported similar results for the pelagic stingray Dasyatis violacea. However, juvenile survival has been reported as having the greatest impact on population growth rate for sharks in a variety of studies (Heppell et al. 1999, Brewster-Geisz \& Miller 2000, Cortés 2002). This shift in importance from juvenile survival for sharks to adult survival for batoids may be explained by differences in their life histories. Rays appear to reproduce at an earlier age in relation to their longevity than many sharks, resulting in rays having a relatively shorter juvenile stage and a relatively longer adult stage (Martin \& Cailliet 1988, Neer \& Cailliet 2001, Frisk et al. 2002). If rays generally had relatively longer adult stages than sharks, this would act to amplify the importance of their adult survival rates because individual age elasticities are summed to obtain single values for juveniles and for adults.

Additional measurements and laboratory experiments designed to estimate specific components of the bioenergetics model would allow for increased accuracy and precision in bioenergetics model predictions. Values of parameters related to specific dynamic 
action, egestion, excretion, and the multiplier representing the metabolic cost of activity used in the model, were all obtained from the literature. While the estimate of specific dynamic action was experimentally determined for another batoid, all the other parameter values were based on experiments with sharks, not rays. Error can be introduced by utilizing parameter estimates from different taxa (Pepin \& Miller 1993), and this error could bias simulated growth results (Bartell et al. 1986).

The assumption of a closed population and densityindependent growth, survival, and reproduction, while common for demographic analysis, may not hold true for cownose rays (Schwartz 1990, BrewsterGeisz \& Miller 2000). Cownose rays are known to undertake long-distance migrations (Schwartz 1990); however, the details of these migrations within the Gulf of Mexico are currently unknown. The metabolic costs of migration were not explicitly incorporated into our bioenergetics model. Should these costs be significantly different (most likely greater) than the metabolic cost of normal activity as presently represented in the bioenergetics model, the results presented here could change. Furthermore, changes in species distribution may occur under altered temperatures (Hopkins \& Cech 2003, Simpfendorfer \& Heupel 2004). Despite the documentation of density-dependent regulation for a variety of teleost species (Rose et al. 2001), very little empirical evidence exists to judge the importance of density dependence in elasmobranchs (Sminkey \& Musick 1995, Carlson \& Baremore 2003). Shifts in age at maturity and juvenile survivorship are the most likely mechanism for compensation in sharks, as most species have a limited capacity for increased fecundity due to physical constraints (Cortés 2002).

Previous demographic analyses of elasmobranchs have been conducted using life table and age-structured matrix projection approaches (Sminkey \& Musick 1996, Simpfendorfer 1999, Cortés 2002, Frisk et al. 2002) or stage-based modeling (Brewster-Geisz \& Miller 2000, Frisk et al. 2002, Mollet \& Cailliet 2002). In the majority of these studies, age- or stage-specific survivorship, maturity, and fecundity had to be inferred from a variety of sources and from information on other species. Furthermore, natural mortality was often assumed to be a constant, when in reality, mortality rate is likely size-dependent (Sminkey \& Musick 1996, Cortés 1998, Simpfendorfer 1999, Frisk et al. 2002). Our coupling of an individual-based bioenergetics model with a matrix projection model offers a potentially powerful approach for relating how, with limited to moderate information, changes in environmental variables and habitat that affect individual growth can be expressed as population-level responses.
Acknowledgements. Thanks to A. Adamack, C. Murphy, and S. Sable for assistance to J.A.N. with modeling issues. Thanks also to B. A. Thompson for discussions on the biological aspects of the study. J.A.N. received support for this research from the National Marine Fisheries Service/National Sea Grant Joint Fellowship Program in Population Dynamics and Marine Resource Economics.

\section{LITERATURE CITED}

Bartell SM, Breck JE, Gardner RH, Brenkert AL (1986) Individual parameter perturbation and error analysis of fish bioenergetics models. Can J Fish Aquat Sci 43:160-168

Bigelow HB, Schroeder WC (1953) Fishes of the western North Atlantic. Part II. Sawfishes, guitarfishes, skates, and rays. Memoir of the Sears Foundation for Marine Research, Yale University, New Haven, CT, p 469-477

Bradley JL (1996) Prey energy content and selection, habitat use and daily ration of the Atlantic stingray, Dasyatis sabina. MS thesis, Florida Institute of Technology, Melbourne, FL

Brandt SB, Hartman KJ (1993) Innovative approaches with bioenergetics models: future applications to fish ecology and management. Trans Am Fish Soc 122:731-735

Brett JR, Groves TDD (1979) Physiological energetics. In: Hoar WS, Randall DJ (eds) Fish physiology Vol VII. Academic Press, New York, p 279-352

Brewster-Geisz KK, Miller TJ (2000) Management of the sandbar shark, Carcharhinus plumbeus: implications of a stage-based model. Fish Bull 98:236-249

Carlson JK, Baremore IE (2003) Changes in biological parameters of Atlantic sharpnose shark Rhizoprionodon terraenovae in the Gulf of Mexico: evidence for density-dependent growth and maturity? Mar Freshw Res 54:227-234

Carlson JK, Goldman KJ, Lowe CG (2004) Metabolism, energetic demand, and endothermy. In: Carrier JC, Musick JA, Heithaus MR (eds) Biology of sharks and their relatives. CRC Press, Boca Raton, FL, p 201-222

Caswell H (2001) Matrix population models: construction, analysis, and interpretation, 2nd edn. Sinauer Associates, Sunderland, MA

Compagno LJV (1990) Alternative life history styles of cartilaginous fishes in time and space. Environ Biol Fishes 28: $33-75$

Cortés E (1998) Demographic analysis as an aid in shark stock assessment and management. Fish Res 39:199-208

Cortés E (2002) Incorporating uncertainty into demographic modeling: application to shark populations and their conservation. Conserv Biol 16:1048-1062

Cortés E (2004) Life history patterns, demography, and population dynamics. In: Carrier JC, Musick JA, Heithaus MR (eds) Biology of sharks and their relatives. CRC Press, Boca Raton, FL, p 449-469

Du Preez HH, McLachlan A, Marais JFK (1988) Oxygen consumption of two nearshore marine elasmobranchs, Rhinobatos annulatus (Muller \& Henle, 1841) and Myliobatus aquila (Linnaeus, 1758). Comp Biochem Physiol A 89: 283-294

Du Preez HH, McLachlan A, Marais JFK, and Cockcroft AC (1990) Bioenergetics of fishes in a high-energy surf-zone. Mar Biol 106:1-12

Frisk MG, Miller TJ, Fogarty MJ (2002) The population dynamics of little skate Leucoraja erinacea, winter skate Leucoraja ocellata, and barndoor skate Dipturus laevis: predicting exploitation limits using matrix analyses. ICES J Mar Sci 59:576-586 
Gotelli NJ (2001) A primer of ecology, 3rd edn. Sinauer Associates, Sunderland, MA

Gruber SH (1984) Bioenergetics of the captive and freeranging lemon shark (Negaprion brevirostris). Proc Annu Conf Am Assoc Zool Park Aquarium 60:340-373

Hanson PC, Johnson TB, Schindler DE, Kitchell JF (1997) Fish bioenergetics 3.0. University of Wisconsin-Madison Center for Limnology. Wisconsin Sea Grant Institute, WI

Heppell SS, Crowder LB, Menzel TR (1999) Life table analysis of long-lived marine species with implications for conservation and management. In: Musick JA (ed) Life in the slow lane: ecology and conservation of long-lived marine animals. Am Fish Soc Symp 23, Bethesda, MD, p 137-146

Heppell SS, Caswell H, Crowder LB (2000) Life histories and elasticity patterns: perturbation analysis for species with minimal demographic data. Ecology 81(3):654-665

Hill DK, Magnuson JJ (1990) Potential effects of global climate warming on the growth and prey consumption of Great Lakes fish. Trans Am Fish Soc 119:265-275

Hoenig JM (1983) Empirical use of longevity data to estimate mortality rates. Fish Bull 82:898-903

Hopkins TE, Cech JJ (2003) The influence of environmental variables on the distribution and abundance of 3 elasmobranchs in Tomales Bay, California. Environ Biol Fishes 66:279-291

Kennedy VS, Twilley RR, Kleypas JA, Cowan JH Jr, Hare SR (2002) Coastal and marine ecosystems and global climate change: potential effects on US resources. Pew Center on Global Climate Change, Arlington, VA. Available at: www.pewclimate.org/global-warming-in-depth/all_reports/ coastal_and_marine_ecosystems/index.cfm

Lowe CG (2002) Bioenergetics of free-ranging juvenile scalloped hammerhead sharks (Sphyrna lewini) in Kane'ohe Bay, O'ahu, Hawai'i. J Exp Mar Biol Ecol 278:141-156

Martin LK, Cailliet GM (1988) Age and growth determination of the bat ray, Myliobatis californica Gill, in central California. Copeia 1988:762-773

Matern SA, Cech JJ, Hopkins TE (2000) Diel movements of bat rays, Myliobatis californica, in Tomales Bay, California: evidence for behavioral thermoregulation? Environ Biol Fishes 58:173-182

McEachran JD, Fechhelm JD (1998) Fishes of the Gulf of Mexico. Vol 1. University of Texas Press, Austin, TX

Mollet HF, Cailliet GM (2002) Comparative population demography of elasmobranchs using life history tables, Leslie matrices and stage-based matrix models. Mar Freshw Res 53:503-516

Musick JA (1999) Ecology and conservation of long-lived marine animals. In: Musick JA (ed) Life in the slow lane: ecology and conservation of long-lived marine animals. Am Fish Soc Symp 23, Bethesda, MD, p 1-10

Neer JA (2005) Aspects of the life history, ecophysiology, bioenergetics, and population dynamics of the cownose ray, Rhinoptera bonasus, in the northern Gulf of Mexico. PhD dissertation, Louisiana State University and Agricultural and Mechanical College, Baton Rouge, LA

Neer JA, Cailliet GM (2001) Aspects of the life history of the Pacific electric ray, Torpedo californica (Ayres). Copeia 2001:842-847

Neer JA, Thompson BA (2005) Life history of the cownose ray, Rhinoptera bonasus, in the northern Gulf of Mexico, with comments on geographic variability in life history traits. Environ Biol Fish 73:321-331

Neer JA, Carlson JK, Thompson BA (2006) Standard oxygen consumption of seasonally acclimatized cownose rays,

Editorial responsibility: Howard Browman (Associate Editor-inChief), Storebø, Norway
Rhinoptera bonasus (Mitchill 1815), in the northern Gulf of Mexico. Fish Physiol Biochem 32:67-71

Neill WH (1979) Mechanisms of fish distribution in heterothermal environments. Am Zool 19:305-317

Pepin P, Miller TJ (1993) Potential use and abuse of general empirical models of early life history processes in fish. Can J Fish Aquat Sci 50:1343-1345

Roff DA (1992) The evolution of life histories: theory and analysis. Chapman \& Hall, New York

Rose KA, Cowan JH, Winemiller KO, Meyers RA, Hilborn R (2001) Compensatory density dependence in fish populations: importance, controversy, understanding and prognosis. Fish Fish 2:293-327

Russell RW (1999) Comparative demography and life history tactics of seabirds: implications for conservation and marine monitoring. In: Musick JA (ed) Life in the slow lane: ecology and conservation of long-lived marine animals. Am Fish Soc Symp 23, Bethesda, MD, p 51-76

Schindler DE, Essington TE, Kitchell JF, Boggs C, Hilborn R (2002) Sharks and tunas: Fisheries impacts on predators with contrasting life histories. Ecol Appl 12:735-748

Schwartz FJ (1990) Mass migratory congregations and movements of several species of cownose rays, genus Rhinoptera: a world-wide review. J Elisha Mitchell Sci Soc 106: 10-13

Simpfendorfer CA (1999) Demographic analysis of the dusky shark fishery in southwestern Australia. In: Musick JA (ed) Life in the slow lane: ecology and conservation of long-lived marine animals. Am Fish Soc Symp 23, Bethesda, MD, p 149-160

Simpfendorfer CA, Heupel MR (2004) Assessing habitat use and movement. In: Carrier JC, Musick JA, Heithaus MR (eds) Biology of sharks and their relatives. CRC Press, Boca Raton, FL, p 553-572

Sminkey TR, Musick, JA (1995) Age and growth of the sandbar shark, Carcharhinus plumbeus, before and after population depletion. Copeia 1995:871-883

Sminkey TR, Musick JA (1996) Demographic analysis of the sandbar shark, Carcharhinus plumbeus, in the western North Atlantic. Fish Bull 94:341-347

Smith JB (2004) A synthesis of potential climate change impacts on the U.S. Pew Center on Global Climate Change, Arlington, VA. Available at: www.pewclimate.org/ global-warming-in-depth/all_reports/synthesisimpacts/ index.cfm

Smith JW, Merriner JV (1985) Food habits and feeding behavior of the cownose ray, Rhinoptera bonasus, in lower Chesapeake Bay. Estuaries 8:305-310

Smith JW, Merriner JV (1987) Age and growth, movements and distribution of the cownose ray, Rhinoptera bonasus, in Chesapeake Bay. Estuaries 10:153-164

Trent L, Parshley DE, Carlson JK (1997) Catch and bycatch in the shark drift gillnet fishery off Georgia and east Florida. Mar Fish Rev 59:19-28

Van Dykhuizen G, Mollet HF (1992) Growth, age estimation and feeding of captive sevengill sharks, Notorynchus cepedianus, at the Monterey Bay Aquarium. Aust J Mar Freshw Res 43:297-318

Wetherbee BM, Gruber SH (1993) Absorption efficiency of the lemon shark Negaprion brevirostris at varying rates of energy intake. Copeia 1993:416-425

Wetherbee BM, Cortés E (2004) Food consumption and feeding habits. In: Carrier JC, Musick JA, Heithaus MR (eds) Biology of sharks and their relatives. CRC Press, Boca Raton, FL, p 225-246

Submitted: January 11, 2006; Accepted: June 7, 2006 Proofs received from author(s): December 18, 2006 